\title{
Coerência Textual: Um Estudo com Jovens e Adultos
}

\author{
Fabiola Gonçalves ${ }^{1}$ \\ Maria da Graça Bompastor Borges Dias ${ }^{2}$ \\ Universidade Federal de Pernambuco
}

\begin{abstract}
Resumo
A coerência é um fenômeno lingüístico responsável pela construção de sentido que garante a interpretabilidade de um texto. As investigações conduzidas pela psicologia cognitiva têm investido esforços no exame da coerência a partir da perspectiva daqueles que recebem o texto. Este estudo examinou se o estabelecimento da coerência textual está relacionado à aquisição da leitura e da escrita com jovens e adultos, em processo de alfabetização, em uma situação de produção de texto. Alunos entre 15 a 45 anos, matriculados no $1^{\circ}$ e $2^{\circ}$ ciclos da Educação Básica de Jovens e Adultos de uma escola pública, foram individualmente solicitados a produzir oralmente uma história original. As histórias foram analisadas em função de indicadores específicos, agrupados em um sistema de análise, o qual expressa níveis distintos acerca do estabelecimento da coerência. Comparações entre os ciclos foram realizadas. Os resultados obtidos corroboram estudo realizado com crianças. Há indicadores mais fáceis de serem estabelecidos do que outros. Pode-se argumentar que a escolaridade contribui para o estabelecimento da coerência na produção de história.
\end{abstract}

Palavras-chave: Coerência de texto; produção oral de histórias; processo de alfabetização.

Text Coherence: A Study with Youths and Adults

\begin{abstract}
Coherence is a linguistic phenomenon responsible for meaning construction which assures the understanding of a text. Investigations led by cognitive psychology, have invested efforts on the analysis of coherence from the perspective of those who receive the text. This study examined if the establishment of textual coherence is related to the acquisition of reading and writing amidst youths and adults, in literacy process, in a situation of text production. Fifteen to 45-year-old students, enrolled in the 1st and 2nd cycles of Basic Education for Youths and Adults at a public school, were individually requested to produce a original. The stories were analyzed according to specific indicators, contained in an analysis system, which expresses different levels concerning the establishment of coherence. Comparisons among the cycles were carried out. The results obtained reinforce a study performed with children. There are some indicators easier to be established than others. It can be said that formal education contributed to the establishment of coherence in stories production.

Keywords: Text coherence; oral production of stories; literacy process.
\end{abstract}

A língua escrita tem funções bem definidas nas sociedades e se manifesta através de diferentes registros. A variedade de contextos sociais envolve uma infinidade de textos que versam sobre os mais diferentes conteúdos e que são organizados de modos distintos e característicos.

Os diferentes gêneros de texto podem ser considerados um fenômeno cognitivo e social. Na perspectiva cognitiva, observa-se um interesse em examinar os processos de desenvolvimento que atuam na estruturação e representação que a criança apresenta sobre determinado gênero de texto. Por exemplo, em relação à história, há estudos que procuram entender como ocorre a aquisição e o desenvolvimento de um esquema narrativo em crianças tanto em histórias orais (Ex.: Spinillo, 1993; Spinillo \& Pinto, 1994) como em histórias escritas (Ex.: Rego, 1986).

\footnotetext{
${ }^{1}$ Apoio CNPq e FACEPE.

${ }^{2}$ Endereço para correspondência: Av. Baira-Mar, 520, 81, 54400 010, Piedade, Jaboatão, PE. Fone: (81) 32718272, Fax: 32711843.E-mail: mdias@npd.ufpe.br
}

Na perspectiva social, a idéia de gênero é expandida para caracterizar qualquer discurso, oral, conversacional, etc. Para Bakhtin (1986, citado em Hicks, 1991), gênero é um componente essencial de significados, podendo ser de dois tipos: secundários e primários. Os gêneros secundários (textos científicos, novelas) derivam-se dos primários, os quais têm origem nas situações e contextos da vida diária.

Hicks (1991) focaliza as origens sociolingüísticas do conhecimento sobre gêneros. $\mathrm{O}$ autor considera esta habilidade como estreitamente relacionada ao conhecimento social derivado das interações que o indivíduo estabelece, desenvolvendo assim, múltiplas formas de representar seu conhecimento sobre gêneros de textos, conhecimento derivado, entre outros aspectos, das experiências e contatos que o indivíduo tem com textos, o que lhe permite adaptar a linguagem a situações específicas de uso.

Segundo Smith (1988), cada tipo de texto tem seu próprio estilo ou esquema (convenções, layout, tipologia e estilo, convenções lingüísticas, conteúdo específico etc), o 
que o destingue de outros gêneros de textos. Um gênero narrativo (Ex.: história) não possui as mesmas características e organização que um gênero epistolar (Ex.: carta). Para cada gênero existem relações internas características denominadas estruturas do discurso.

De acordo com Tannen (1982), as diferenças estruturais entre textos deveriam ser atribuídas não tanto a diferenças gerais entre fala e escrita, mas a diferença de gênero e registro que dependem dos objetivos comunicativos do narrador (falante ou escritor) e do contexto da comunicação. Não se escreve uma carta usando a mesma organização lingüística e os mesmos componentes estruturais de uma história. Assim sendo, o texto é muito mais do que uma simples seqüência de enunciados. Cada estilo de texto envolve conteúdo, função social, organização lingüística e componentes estruturais específicos que o definem e o diferenciam dos demais.

Em geral, a escola não tem contribuído para que os alunos tenham uma concepção de linguagem escrita como uma forma de comunicação, e nem tampouco como instrumento para apropriação de outros conhecimentos escolares. Os usos e funções da língua escrita no contexto escolar diferem acentuadamente dos usos sociais que a língua escrita tem no cotidiano de uma sociedade letrada. No contexto escolar a língua escrita é tratada como:

uma entidade abstrata, sem razão social que extrapole os objetivos puramente acadêmicos, retirando seu significado funcional. Os usos escolares da escrita parecem ser bastante restritos, ignorando sua dimensão comunicativa e menosprezando o seu papel como instrumento através do qual o indivíduo leitor tem acesso a outros conhecimentos. (Spinillo \& Roazzi, 1988, p. 82)

Os alunos da Educação Básica de Jovens e Adultos já possuem uma experiência ampla com a língua escrita, embora ainda não a dominem. Considerando, então, o papel que a escola tem na formação desse aluno leitor/escritor, o presente estudo examinou, a partir da habilidade de produção, o conhecimento que adultos, com pouca ou nenhuma escolarização, tem acerca dos componentes estruturais envolvidos no estabelecimento da coerência em relação a um texto comumente veiculado em uma sociedade letrada: a história.

Segundo Stein e Policastro (1984), a prática de contar história é um dos muitos usos da língua em nossa sociedade e se constitui em uma prática cultural que adquire tanto uma função social, viabilizando a preservação da cultura de uma civilização (Ex.: instruir outros, explicar fenômenos naturais ou comunicar os códigos sociais e morais da sociedade); como uma função de reorganizar a experiência pessoal.
Como mencionado, uma análise desta natureza requer tanto um enfoque cognitivo como social. Entretanto, nesta investigação a ênfase recai sobre o enfoque cognitivo, sem que isto signifique negar o papel crucial dos aspectos sociais envolvidos no desenvolvimento acerca dos princípios de estabelecimento da coerência.

\section{Coerência e Coesão Textuais}

A textualidade é um fenômeno lingüístico que se constitui a partir da coerência e da coesão presentes nos textos veiculados nas práticas sociais as quais se encontram inseridos. Neste sentido, mesmo a coesão não vem sendo alvo de interesse do presente estudo, faz-se necessário uma apresentação sumária de algumas concepções, à luz do referencial teórico da Lingüística de Textos, que revelam as relações existentes entre a coesão e coerência textual.

A comunicação entre usuários da língua não se estabelece através de frases isoladas, o homem se comunica por meio de textos e existem diversos fenômenos lingüísticos que só podem ser explicados no interior do texto. Koch e Fávero (1988) salientam que os lingüistas procuram desenvolver gramáticas textuais por causa das lacunas apresentadas pelas gramáticas de frase, no que se refere, principalmente, “à co-referência, à pronominalização, à seleção dos artigos, à ordem das palavras no enunciado, à relação tópico-comentário, à entoação, às relações entre sentenças não ligadas por conjunções, à concordância de tempos verbais" (p. 12), e outros. Para as autoras, esses elementos dependem do texto ou do contexto para que possam ser devidamente explicados.

Os trabalhos sobre coesão e coerência textuais não se restringem à esfera dos estudos lingüísticos tradicionais. Pesquisas desenvolvidas por muitos estudiosos fornecem uma série de elementos imprescindíveis a uma visão global da interação comunicativa.

Paralelamente a isso, surge, nos trabalhos mais recentes, uma visível necessidade de integração, que leva alguns representantes da teoria do texto (Beaugrande, 1996; Beaugrande \& Dressler, 1981; Bernárdez, 1982; Charolles, 1978, 1979; Halliday \& Hasan, 1976; Koch \& Travaglia, 1999; Marcuschi, 1983; Tannen, 1984; Van Dijk, 1981; Widdowson, 1978) a introduzirem em suas propostas noções de diversas correntes.

O trabalho desses autores caracteriza-se pela preocupação em abordar os vários aspectos da linguagem em termos de sua utilização. $\mathrm{O}$ texto visto como uma unidade de sentido, atualizada no momento da interação comunicativa, é um dos aspectos discutidos por esses estudiosos.

Halliday e Hasan (1976) consideram que a coesão tanto pode ser gramatical como lexical, no entanto, apenas os 
mecanismos de coesão não fariam do texto um texto. Eles afirmam que o texto prescinde de um certo grau de coerência para estabelecer o envolvimento dos vários componentes interpessoais com outras formas de influência na situação de fala. Neste sentido "A coesão é interna (lingüística) e a coerência, externa, pois diz respeito aos contextos de situação" (p. 30).

Widdowson (1978) destaca a dimensão pragmática ao conceituar a coerência. $\mathrm{O}$ autor afirma ser a coesão o processo através do qual as frases ou partes são conectadas para garantir o desenvolvimento proposicional, revelandose através de índices formais sintáticos, sem apelo ao pragmático, ou seja, a coesão esta ligada aos aspectos gramaticais. Ao passo que a coerência está diretamente ligada ao desenvolvimento dos atos ilocucionais, por meio das proposições, possibilitando a dedução das ligações proposicionais implícitas, a partir de uma interpretação dos atos ilocucionais. Ao conceituar a coerência, a dimensão pragmática é destacada pelo autor, ou seja, a situação de fala entre os interlocutores é relevante para a construção de sentido no texto.

Para Beaugrande (1996), o texto é um sistema constituído por um conjunto de elementos inter-relacionados. Tais elementos mostram as opções realizadas por um usuário a partir da virtualidade do sistema lingüístico. Sendo assim, o texto é um sistema real constituído por procedimentos específicos de manipulação de um sistema virtual. Para o autor, a análise da coerência, dentro de uma visão global da interação comunicativa, passa a envolver, necessariamente, desde as virtualidades do código até os efeitos de sentido obtidos pelas atualizações discursivas, considerando-se os aspectos cognitivos e o uso predominantemente argumentativo da linguagem.

Para Marcuschi (1983), a coesão está relacionada à estrutura superficial do texto e à sua organização linear sob o aspecto estritamente lingǘ́stico. Ao passo que a coerência é o produto de uma conexão conceitual-cognitiva e estruturação do sentido, a qual, em geral, manifesta-se macrotextualmente estando relacionado à potencialidade de transmissão de conhecimentos ou conteúdos de modo a viabilizar a existência de sentido. $\mathrm{O}$ autor ressalta, inclusive, que há textos que não têm coesão, porém a textualidade ocorre no nível da coerência. Para ele, o texto pode apresentar nuances acerca do sentido: indeterminado ou pouco claro; ambíguo, dando margem a várias possibilidades de sentido; e polivalente que é a situação em que o narrador produz intencionalmente vários sentidos possíveis. Diante desta perspectiva, a coerência é um processo global responsável pela formação do sentido que garante a compreensibilidade de um texto, não havendo uma continuidade de sentido, o texto torna-se incoerente.
Koch e Travaglia (1999) consideram que a coerência se estabelece na interação, na interlocução, numa situação comunicativa entre dois usuários. Esses autores caracterizam a coerência como uma continuidade de sentidos perceptível no texto, resultando numa conexão conceitual-cognitiva entre os elementos do texto. Este processo de conexão, além dos fatores lógicos, depende de fatores socioculturais diversos. Ou seja, há uma interligação entre os processos cognitivos operantes dos usuários, os quais caracterizam a coerência à medida que possibilitam criar um mundo textual em face do conhecimento de mundo registrado na memória, o que levaria a compreensão do texto; e os fatores interpessoais (formas de influência do falante na situação de fala, as intenções comunicativas dos interlocutores), evidenciando a importância da dimensão pragmática da coerência na construção de sentido.

Segundo Koch e Travaglia (1999), a coerência dá textura à seqüência lingüística, entendendo-se por textura ou textualidade aquilo que converte uma seqüência lingüística em texto e não em um amontoado de palavras. A seqüência é percebida como texto quando aquele que o recebe é capaz de percebê-lo como uma unidade significativa global.

De acordo com as concepções teóricas citadas, o fenômeno da coerência textual tem sido caracterizado através do princípio de interpretablidade do texto, abrangendo diversos fatores: lingüísticos, cognitivos e interacionais. A coerência determina quais elementos constituem a estrutura superficial do texto e como estes se organizam na seqüência lingüística.

A coerência abrange, além da coesão textual, outros fatores de ordem diversas, tais como, elementos lingüísticos, conhecimento de mundo, conhecimento partilhado, situacionalidade, informatividade, intertextualidade, intencionalidade e aceitabilidade. Os elementos lingüísticos funcionam como pistas para ativar o conhecimento de mundo e dizem respeito à relação que se estabelece entre o texto e o seu contexto. Esses elementos são necessários para se obter a coerência mas não são os únicos responsáveis para dar o significado a uma narrativa.

Koch e Travaglia (1999), Beaugrande e Dressler (1981) e Van Dijk (1981) revelam que esses elementos assumem um papel essencial no estabelecimento da coerência em textos.

Koch e Travaglia (1999) dão relevância à relação estabelecida entre os aspectos lingüístico, conceitual-cognitivo (conhecimento de mundo) e pragmático, reforçando cada vez mais a importância das marcas lingüísticas como pistas à construção do sentido e, portanto, da coerência do texto.

Para Beaugrande e Dressler (1981), há uma relação entre os níveis gramatical e o conceitual do texto, sendo a cadeia gramatical compreendida através de pequenas partes 
do texto, enquanto que a cadeia conceitual abrangeria todo o texto.

Van Dijk (1981) ressalta a relação dos elementos lingüísticos com o pragmático, apresentando a importância dos traços lingüísticos do enunciado, em todos os níveis (fonético/fonológico, morfológico/lexical, sintático/ semântico) para apreender os atos de fala realizados e, portanto, estabelecer a coesão pragmática.

A coerência se constitui ao mesmo tempo em termos semânticos, pragmáticos, e sintático (lingüística e gramatical). Neste sentido, a coesão e a coerência estão intimamente relacionadas no processo de produção e compreensão textual; a coerência se estabelece na interlocução.

Para Koch e Travaglia (1999), o conhecimento de mundo resulta de aspectos socioculturais estereotipados. $\mathrm{O}$ processo de armazenamento na memória não ocorre de forma isolada, sua organização e representação na mente são realizadas através de unidades completas de conhecimentos estereotipados, denominados de conceitos e modelos cognitivos globais.

É o conhecimento de mundo que favorece o processo de compreensão que se realiza por meio da construção do mundo textual, da articulação entre os elementos do texto e do estabelecimento da continuidade de sentido. Assim, o conhecimento de mundo ou saber enciclopédico se constitui em um dos fatores responsáveis pela construção de sentido e, consequentemente, pela coerência textual.

Os modelos cognitivos são, em geral, aprendidos através da experiência diária. Além do conhecimento de mundo existe também o conhecimento científico, aprendidos nas escolas e nos livros. Mas para que se possam estabelecer a coerência textual, é necessário que haja uma correspondência entre o conhecimento ativado através do texto e o conhecimento de mundo.

Os modelos cognitivos propostos por Beaugrande e Dressler (1997) envolvem frames, scripts, planos, esquemas e superestruturas ou esquemas textuais. Estes são responsáveis pelo processo de correspondência entre o conhecimento ativado no texto e o conhecimento de mundo.

Os frames são modelos globais que contêm o conhecimento do senso comum sobre um conceito central sem uma ordem pré-estabelecida. Quanto aos scripts, os autores afirmam que os mesmos são conjuntos de conhecimentos sobre modos de agir em cada cultura, inclusive, em termos de linguagem. Os planos se configuram acerca do conjunto de conhecimentos sobre como agir para proceder em determinada situação em relação a uma meta a ser atingida. Já os esquemas são constituídos através de conceitos convencionais referentes a objetos, situações, eventos e ações. Ao contrário dos frames, os esquemas apresentam elementos interligados por relações de causalidade e proximidade temporal. Por fim, as superestruturas ou esquemas textuais são conjuntos de conhecimento armazenados na memória a respeito dos mais diversos tipos de textos, adquiridos à medida que se entra em contato com esses tipos e faz-se comparações entre eles.

Já o conhecimento partilhado diz respeito aos conhecimentos que os indivíduos têm em comum acerca de determinados textos, estando relacionado à forma pela qual o indivíduo constrói o sentido do texto através da integração entre informações novas e conhecidas.

Neste sentido, caso o texto contenha exclusivamente informação conhecida não realiza o seu propósito comunicativo; se apresentar somente informação nova, o interlocutor não consegue estabelecer a coerência textual. Sendo assim, Koch e Travaglia (1999), Koch e Travaglia (1999) ressaltam o papel fundamental do conhecimento partilhado para a construção de sentido, ou seja, a coerência revela-se em seqüências conversacionais do tipo pergunta/ resposta em que esta não tem ligação lingüística ou de conteúdo explícito.

Segundo Beaugrande (1997), a situacionalidade, a intencionalidade e aceitabilidade, a informatividade e intertextualidade são fatores pragmáticos relevantes no processo de estabelecimento da coerência.

A situacionalidade refere-se ao conjunto de fatores que tornam um texto essencial em uma situação de comunicação corrente ou passível de ser constituída. Tanto a intencionalidade como a aceitabilidade são fatores que se constituem através do princípio de cooperação entre os interlocutores, pois quem produz um texto tem sempre a intenção de que este seja compreendido, e quem o recebe espera que o mesmo faça sentido. Já a informatividade diz respeito ao grau de novidade e previsibilidade contidos em um texto, podendo, por isso, dificultar ou facilitar a compreensão do texto. A intertextualidade envolve as diversas maneiras pela quais a produção e recepção de um texto dependem do conhecimento prévio de outros textos por parte dos interlocutores, ou seja, está relacionado aos fatores que tornam a utilização de um texto dependente de um ou mais textos previamente existentes.

Van Dijk e Kintsch (1983) classificam a coerência em dois tipos: uma coerência local que está relacionada às partes do texto, situada a nível das sentenças ou das proposições, e em coerência global, a qual relaciona-se ao texto como um todo. Estes autores enfatizam também, o papel fundamental da coerência em diversos níveis lingüísticos. Um desses níveis - o nível semântico - se constitui na relação entre os significados dos elementos locais ou entre a totalidade textual. Já o nível sintático representa o uso de recursos coesivos e sintagmas nominais como recursos 
auxiliares indispensáveis à coerência semântica do texto. $\mathrm{O}$ nível estilístico, que se constitui nas características lingüísticas de um referido tipo de texto. E por último, o pragmático, o qual está relacionado à função comunicativa na qual o texto encontra-se inserido, caracterizados pelos atos de fala entre os interlocutores.

Os autores considerados enfatizam que a coerência constitui-se, em grande parte, no nível macro-textual. Van Dijk (1973) e Van Dijk (1971, 1977, citados em Fávero \& Koch, 1988) argumenta que os aspectos macro-lingüísticos se constituem através da estrutura do texto e da relação temática e semântica geral que define o significado como um todo. A abordagem macro-analítica de um texto enfatiza a coerência em si, tanto ao longo do tópico como em relação aos componentes estruturais característicos de um dado gênero de texto.

O gênero de um texto seja narrativo, descritivo ou dissertativo, apresenta uma estética, organização lingüísticas e componentes estruturais particulares cuja existência permite que se faça a distinção entre os diversos tipos de textos. No caso de uma história, é possível pensar que a coerência estaria relacionada aos elementos estruturais que a compõe, como: do tema sobre o qual versa a história, da descrição dos personagens, do cenário onde ocorrerão os eventos e do desfecho da história que culmina com a resolução da trama.

Esses aspectos são tratados na literatura como pertencentes à gramática de histórias (Ex.: Johnson \& Mandler, 1980; Mandler \& Johnson, 1977; Prince, 1973; Stein \& Policastro, 1984). A idéia de que a produção de uma história coerente requer a presença desses componentes estruturais é também aceita por Stein (1998) e Stein e Glenn (1979), cuja ênfase diz respeito à incorporação de todos os elementos episódicos em um enredo coerente e lógico, com relações de causalidade. Neste sentido, tomando como referencial os aspectos estruturais acima colocados, é possível pensar que a coerência de uma história estará comprometida caso haja a ausência de um ou mais componentes.

\section{A Coerência na Perspectiva do Produtor do Texto}

De acordo com as considerações realizadas, o estudo da coerência vem sendo intensamente pesquisado pela Lingüística de Texto. Porém, os próprios lingüistas reconhecem a necessidade de estabelecer um enfoque multidisciplinar no estudo da coerência em relação às habilidades de produção e de compreensão de textos. Neste sentido, a Psicologia Cognitiva, dentre as diversas áreas do conhecimento relativas ao comportamento humano, surge como uma alternativa que pode contribuir para fornecer uma visão de desenvolvimento da competência do indivíduo quanto aos processos relativos ao estabelecimento da coerência.
Em geral, as pesquisas tendem a investigar a coerência na perspectiva do receptor do texto, ou seja, aquele que o compreende. Ao passo que as pesquisas na perspectiva de quem produz o texto ainda são escassas. No entanto, a seguir serão brevemente apresentados dois estudos que investigaram a coerência na produção de histórias.

Bennett-Kastor (1983, citado em Spinillo \& Martins, 1997) investigou o uso de sintagmas nominais com crianças de 2 a 5 anos na produção de uma história. O objetivo do estudo foi o de analisar como eram conectados os eventos uns com os outros em uma história. Nesta investigação, os indicadores do nível de coerência da história produzida pela criança se constituíam através da reiteração e manutenção desses sintagmas nominais (especialmente eventos e personagens) no decorrer de toda narração.

Foi atribuído um valor de coerência (VC) aos sintagmas nominais (SN) o qual representava o somatório da quantidade de cláusulas que apareciam entre um $\mathrm{SN}$ e a próxima reiteração deste mesmo referente. $\mathrm{O} V \mathrm{~V}$ representava tanto o número de vezes que o sintagma era reiterado, como também à distância entre um $\mathrm{SN}$ e o próximo.

Os resultados desse estudo evidenciaram que as crianças com 2 anos já introduziam SNs na história, apresentando uma reiteração sucessiva em diversas cláusulas. As crianças com 4 e 5 anos produziam histórias mais longas, apresentando tanto um aumento como um maior controle sobre os SNs produzidos, estando presentes ao longo da história. O resultado mais relevante foi que quase todas as crianças que participaram do estudo, alcançaram com sucesso, independente da idade, muitos dos objetivos textuais a elas solicitados no discurso, objetivos estes que se constituíam na qualidade e freqüência de sintagmas nominais presentes nas histórias.

Spinillo e Martins (1997) realizaram um estudo com crianças entre 6 e 7 anos de idade com níveis de escolaridade distintos: pré-escolares que não haviam sido alfabetizadas; as crianças da alfabetização que estavam em fase de aquisição da leitura e escrita; e crianças da $1^{\text {a }}$ série que já haviam sido alfabetizadas, tornando possível que fossem realizadas comparações entre crianças de mesma idade, porém em séries distintas, com o objetivo de examinar o efeito da escolaridade; e também crianças com idades distintas pertencentes a mesma série, com o objetivo de examinar o efeito da idade. Estas crianças eram de nível socioeconômico médio, alunos de escolas particulares da cidade do Recife. Em uma única sessão, as crianças eram solicitadas a produzir uma história original, oralmente.

A análise do corpus de histórias produzidas no estudo foi realizada tendo como ênfase os aspectos macro-textuais, situando-se nos grupos de investigações que contemplam o exame da coerência global. Segundo os autores, os aspectos 
macro-textuais que compõem uma história são constituídos por vários indicadores: pela manutenção do tópico sobre o qual versa a história, pelas características estruturais da história, que em relação à coerência são a manutenção dos personagens ao longo da história; pela relação entre os eventos narrados que precisam está em conexão entre si através dos personagens, e também pela relação entre os eventos presentes no desenvolvimento da história e seu desfecho, o qual se caracteriza por um final envolvendo os personagens numa íntima relação com os demais episódios narrados, contribuindo, portanto, com o estabelecimento da unidade narrativa.

Através dos indicadores dispostos acima, um grupo hierárquico de níveis foi elaborado, relativo à coerência global. Os principais objetivos desse estudo foram: criar um sistema de análise ${ }^{3}$, até então, ausente na literatura em relação à coerência na produção de textos; examinar as dificuldades das crianças em estabelecer a coerência na produção de uma história e a possível relação entre alfabetização e o desenvolvimento desta habilidade. Os resultados evidenciaram que a maior dificuldade encontrada nas crianças envolvidas no estudo consistiu em relacionar e integrar o desfecho da história aos eventos anteriormente narrados. No entanto, este tipo de dificuldade foi menos observado nas crianças alfabetizadas.

A partir do estudo conduzido por Spinillo e Martins (1997), alguns questionamentos foram levantados: será que o sistema de análise elaborado por esses autores se adequa a análise da produção de histórias por adultos? Será que mesmo entre adultos a alfabetização é um fator importante na produção de textos coerentes?

A história é um gênero de texto que apresenta uma unidade de significado com princípios de constituição bastante precisos, sendo possível detectar seu início, desenvolvimento e seu final, envolvendo organização lingüística e componentes estruturais específicos. Neste sentido, ser coerente ao produzir uma história envolve considerar seus princípios de constituição, isto é, os elementos estruturais que a caracterizam como um gênero narrativo específico.

Segundo alguns autores (Ex.: Beaugrande \& Dressler, 1981; Marcuschi, 1983; Van Dijk, 1973), um dos aspectos essenciais no processo de constituição de sentido é o tópico ou tema central sobre o qual o texto é discorrido. No caso específico de uma história, a organização dos eventos gira em torno de um tópico que deve ser mantido na totalidade da narrativa.

\footnotetext{
${ }^{3} \mathrm{O}$ sistema de análise e seus aspectos serão detalhados no item destinado à análise dos dados.
}

Além do tópico, outros aspectos estruturais subsidiam a constituição de sentido no texto. Tomando como referência a organização lingüística delineada pela gramática da história, é possível pensar que a manutenção e integração ao longo de uma narrativa entre os personagens, os eventos narrados e o desfecho podem contribuir para o estabelecimento da coerência.

Foi visto que a coerência é um fenômeno lingüístico de natureza muito complexa, abrangendo vários fatores que concorrem para o seu estabelecimento, seja do ponto de vista daquele que interpreta o texto, seja daquele que o produz. $\mathrm{O}$ enfoque macro-textual no exame da coerência adotado no presente estudo baseia-se nos elementos estruturais ressaltados no estudo conduzido por Spinillo e Martins (1997) acerca da produção de histórias.

Esses autores levantam questionamentos importantes, na medida em que dirigem o foco de análise aos aspectos específicos envolvidos (elementos constituintes e a manutenção do tópico) em relação ao exame da coerência na produção de história:

Existiriam diferentes níveis de coerência entre uma história em que o tema e os personagens principais não são mantidos sistematicamente ao longo da narrativa, e outra em que o tema e os personagens mantêm-se do começo ao final da história? Teriam diferentes níveis de coerência uma história em que o desfecho não apresenta relação estreita com os episódios anteriormente narrados, e uma história em que existe uma relação estreita entre ambos? (Spinillo \& Martins, 1997, p. 229)

A partir das considerações, surgiu a necessidade de examinar como jovens e adultos, com pouca ou nenhuma escolarização, ao produzir uma história, mantêm uma relação de interdependência entre os componentes estruturais envolvidos no estabelecimento da coerência.

Neste sentido, o presente estudo tem como objetivos específicos:

1) Verificar se o sistema de análise elaborado e utilizado por Spinillo e Martins (1997) para avaliar a coerência de histórias produzidas por crianças, adequa-se à avaliação de histórias produzidas por jovens e adultos.

2) Verificar se, em adultos, a alfabetização é um fator importante na produção de textos orais coerentes.

3) Examinar as semelhanças e diferenças entre os resultados do presente estudo e os obtidos com as crianças.

\section{Método}

\section{Participantes}

Participaram desse estudo 40 alunos da Educação Básica de Jovens e Adultos de nível socioeconômico 
baixo, matriculados em um Centro de Ensino Supletivo $(\text { C.E.S. })^{4}$, pertencente ao sistema público estadual de ensino, localizado na cidade de Recife, cuja idade variava entre 15 e 45 anos.

A Educação Básica de Jovens e Adultos é uma modalidade de ensino, constituída, geralmente por dois perfis de alunos: os que nunca freqüentaram a escola e os que, em seu processo de escolarização, apresentam um quadro de evasão e/ou repetência múltiplas, justificadas pelo ingresso ao setor de trabalho informal, para garantir a sobrevivência da família. Neste sentido, procurou-se verificar se os alunos envolvidos no presente estudo haviam tido algum tipo de experiência escolar.

Através da análise da documentação dos alunos envolvidos no estudo, cedida pela secretaria da escola, detectou-se que parte dos alunos pertencentes ao $1^{\circ}$ ciclo e parte dos alunos pertencentes ao $2^{\circ}$ ciclo possuíam experiência escolar prévia.

Em relação a esses casos as professoras alegaram que os alunos passam por um processo seletivo composto de uma avaliação de língua portuguesa e matemática. As habilidades exploradas na avaliação de língua portuguesa são: leitura, compreensão e produção de texto. De acordo com o resultado da avaliação, o aluno é encaminhado ao ciclo de aprendizagem que terá condições de acompanhar. Sendo assim, os participantes envolvidos no presente estudo apresentam as seguintes características:

Grupo 1: 20 participantes matriculados no $1^{\circ}$ ciclo $^{5}$ composto por alunos que estão iniciando a alfabetização, os quais não dominam a leitura e escrita e alunos que chegaram a cursar a $2^{a}$ série do ensino regular, mas apresentam um domínio precário da leitura e da escrita.

Grupo 2: 20 participantes matriculados no $2^{\circ}$ ciclo composto tanto por alunos egressos do $1^{\circ}$ ciclo da Educação de Jovens e Adultos como por alunos que chegaram a cursar a $4^{a}$ série do ensino regular. Estes alunos são alfabetizados e já adquiriram as habilidades de leitura e escrita.

O que diferencia os alunos matriculados no $1^{\circ}$ ciclo dos alunos matriculados no $2^{\circ}$ ciclo, em relação à língua portuguesa, é a aquisição da leitura e da escrita, avaliada

\footnotetext{
${ }^{4}$ O Centro de Ensino Supletivo (C.E.S.), é uma instituição pública estadual que atende a todas as modalidades de ensino pertencentes a Educação Básica ( $1^{\mathrm{a}}$ a $8^{\mathrm{a}}$ série do Ensino Fundamental e Ensino Médio).

${ }^{5}$ A organização curricular através de ciclos de aprendizagem é contemplada nas propostas curriculares elaboradas pelo MEC (Parâmetros Curriculares Nacionais - Ensino Fundamental e Educação de Jovens e Adultos), os quais se encerram ao final de duas séries. No caso da Educação de Jovens e Adultos das escolas públicas estaduais de Pernambuco, o $1^{\circ}$ ciclo corresponde a alfabetização, $1^{\mathrm{a}}$ e $2^{\mathrm{a}}$ séries e o $2^{\mathrm{o}}$ ciclo corresponde a $3^{\mathrm{a}}$ e $4^{\mathrm{a}}$ séries do Ensino Fundamental).
}

através do desempenho do aluno em atividades de leitura, compreensão e produção de textos.

\section{Material}

Foram utilizados gravador e fitas cassetes para o registro das produções orais dos participantes. Também, foram anotadas a identificação (ciclo, nome, data de nascimento e experiência escolar prévia) de cada participante para compor, posteriormente, o protocolo contendo a produção do aluno transcrita pela examinadora.

\section{Procedimento}

Foi solicitado ao aluno, a produção oral de uma história original realizada em uma única sessão. As referidas produções foram gravadas e transcritas pela examinadora, que realizava poucas intervenções durante a narração do participante. A variável independente examinada foi a escolaridade $\left(1^{\circ}\right.$ e $2^{\circ}$ ciclos de aprendizagem).

Inicialmente, em cada sessão, a examinadora enfatizava para o aluno que não se tratava de prova, portanto não havia nota, nem tão pouco certo ou errado. Além disso, foi explicitado que para a realização da tarefa não havia tempo limitado e caso houvesse alguma dúvida o aluno podia pedir esclarecimentos.

A examinadora solicitava ao aluno que produzisse oralmente uma história original.

Para iniciar a tarefa, a examinadora dava o seguinte encaminhamento:

Eu sou uma professora que trabalha com crianças e adoro histórias. Um dia tive a curiosidade de ouvir histórias contadas por adultos que estão estudando como você. A história é um meio muito comum para nós criarmos um mundo de fantasia, de faz-de-conta, explorando ao máximo a nossa imaginação. Por isso eu gostaria que você soltasse a sua criatividade e me contasse uma história que ninguém nunca leu antes, criada por você. Como a história é sua, você pode falar sobre o que você quiser. Procure pensar sobre o que você vai contar nessa história, qual será o lugar, as pessoas ou animais que farão parte da sua história, dos fatos que irão acontecer e como é que terminará a sua história. Eu vou gravar sua história para depois eu poder passar para o papel.

A examinadora, após o término da instrução, deixava claro para o aluno que ele podia organizar a história que iria contar na sua cabeça e quando ele quisesse começar avisasse para que fosse iniciada a gravação.

\section{Resultados}

\section{Categorização das histórias}

As narrativas foram classificadas em quatro níveis por juizes independentes (nível de concordância de 82,5\%). 
As discordâncias foram decididas com o parecer de um terceiro juiz, cujo parecer foi considerado final e que sempre coincidiu com a classificação de um dos dois juizes.

Spinillo e Martins (1997) elaboraram um sistema de análise em relação ao nível de coerência das crianças em situação de produção de história na modalidade oral. No presente estudo, o referido sistema foi adotado.

Para a elaboração do sistema de análise, os autores basearam-se nos princípios de constituição delineados pela gramática de história. Neste sentido, a ênfase incide sobre o estabelecimento da coerência acerca da organização lingüística e dos indicadores específicos característicos em uma história.

Os indicadores foram analisados a partir da manutenção e da conexão estabelecida entre os mesmos nas histórias produzidas pelos participantes envolvidos no estudo. Através de tal análise foi possível perceber que haviam histórias que apresentavam tipos distintos de indicadores, definindo graus de coerência também distintos.

As histórias produzidas pelos participantes do presente estudo foram classificadas nos níveis de coerência textual elaborados por esses autores.

Nível I ${ }^{6}$ - O personagem principal pode ser indefinido (P1), ou pode tanto ser mantido ao longo da narração (P3) como desaparecer e retornar ao final da narrativa, ou ser substituído por outro (P2). Há mudança de tópico ao longo da narração sem que se retorne ao mesmo no final (T1). Não se observa um evento principal definido (E1), nem tampouco um desfecho (D1). São histórias que se caracterizam por mudanças de tópicos e de eventos que sucedem desconectadamente, o que dificulta a compreensibilidade do texto, o qual termina abruptamente.

Nível II - como no nível anterior, o personagem pode ser do tipo P1, P2 ou P3. Entretanto, observar-se a tendência em manter um tema central que, mesmo substituído é retomado ao final da narração (T2). Não se observa um evento principal definido, mas sim, vários eventos sem relação (E1) ou com certa relação entre eles (E2). O desfecho pode não estar presente (D1), ou quando existe não apresenta uma relação com os eventos narrados anteriormente (D2); o que causa uma quebra na cadeia narrativa dificultando a compreensão do texto, o que também é provocado pela mudança de tópico. O que mais diferencia este nível do anterior, é o fato do tópico no Nível II ser tipo T2, indicando uma tendência em mantê-lo ao longo da história. Observase uma certa relação entre os eventos e o desfecho, embora sem uma relação precisa com o desenvolvimento da história.

Nível III - Existe um personagem central que pode ser mantido ao longo da narração (P3) ou desaparecer retornando no final da história (P2). Um mesmo tema central é mantido ao longo de toda a narração (T3). Verificam-se vários eventos sem que possa ser definido o principal, mas conectados entre si (E2), ou um evento bem definido ao longo de toda a narração (E3). Há um desfecho que não apresenta uma relação clara com o evento principal (D2). O que caracteriza essas produções, e ao mesmo tempo as diferencia daquelas classificadas no nível anterior, é o fato do tópico e do evento serem mantidos ao longo de toda narração. A compreensibilidade é, em certo sentido, comprometida uma vez que o desfecho não está em estreita relação com os eventos anteriormente narrados, provocando uma lacuna na cadeia narrativa ao final do texto.

Nível IV - o personagem principal é bem definido, sendo mantido ao longo de toda história (P3), o mesmo ocorrendo com o evento principal (E3) e com o tópico da narração (T3). O desfecho está presente e mantém relação estreita com o evento principal (D3). São histórias que apresentam uma cadeia narrativa conectada e centrada em um tópico bem definido sobre o qual versam os eventos e atuam os personagens. A isto é acrescido o fato de que o desfecho envolve a trama da história e seus

Tabela 1

Frequiencia (Porcentagem) de cada Indicador da Coerência em Função do Ciclo de cada Participante

\begin{tabular}{cccccccccccccc}
\hline & \multicolumn{3}{c}{ Personagem } & \multicolumn{3}{c}{ Tópico } & \multicolumn{3}{c}{ Eventos } & \multicolumn{3}{c}{ Desfecho } \\
\hline & P1 & P2 & P3 & T1 & T2 & T3 & E1 & E2 & E3 & D1 & D2 & D3 \\
& & & & & & & & & & & & \\
$1^{\circ}$ Ciclo & 0 & 0 & 20 & 0 & 5 & 15 & 0 & 8 & 12 & 2 & 10 & 8 \\
& $(-)$ & $(-)$ & $(100)$ & $(-)$ & $(25)$ & $(75)$ & $(-)$ & $(40)$ & $(60)$ & $(10)$ & $(50)$ & $(40)$ \\
$2^{\circ}$ Ciclo & 0 & 0 & 20 & 0 & 2 & 18 & 0 & 4 & 16 & 0 & 4 & 16 \\
& $(-)$ & $(-)$ & $(100)$ & $(-)$ & $(10)$ & $(90)$ & $(-)$ & $(20)$ & $(80)$ & $(-)$ & $(20)$ & $(80)$ \\
Kruskal-Wallis & & 0 & & & 1,52 & & & 1,85 & & & 6,36 & \\
$\chi^{2}$ (gl. = 1) P & 1,00 & & & 0,2177 & & & 0,1730 & & & 0,0083 & \\
\hline
\end{tabular}

${ }^{6}$ No presente estudo, não houve classificação de histórias no nível I. 
personagens. O que mais diferencia este nível dos demais, é a elaboração de um desfecho em estreita conexão com os eventos narrados no desenvolvimento da história.

Inicialmente foi realizado um levantamento dos indicadores da coerência delineados pela gramática de histórias, com o objetivo de verificar as possíveis dificuldades dos alunos nas histórias produzidas.

Foi utilizado o teste Kruskal-Wallis com o objetivo de examinar se existiriam diferenças significativas entre os indicadores da coerência em função dos ciclos de aprendizagem. As diferenças foram observadas apenas em relação ao desfecho $\left(1^{\circ}\right.$ ciclo vs. $2^{\circ}$ ciclo: $\chi^{2} \quad 6,36$, gl. $1, p=0,0083)$.

No geral, pode-se perceber que os jovens e adultos que estão iniciando o processo de alfabetização apresentam dificuldades em relacionar o desfecho ao evento principal e aos episódios narrados ao longo da história. No entanto, os alunos que estão terminando a educação básica de jovens e adultos não apresentam este tipo de dificuldade. Este resultado evidência qual a dificuldade que o aluno, em nível inicial de aquisição da leitura e da escrita, enfrenta na tentativa de produzir uma história coerente.

Ao observar a distribuição dos indicadores (personagem, tópico, evento, desfecho) entre os participantes de cada ciclo, pode-se perceber uma tendência em tipos mais elaborados, entre os participantes $2^{\circ}$ do ciclo.

O personagem (P3) mais elaborado foi identificado em todas as histórias analisadas, conforme disposto na Tabela 1 , constituindo-se no indicador mais fácil de ser mantido ao longo da narrativa. Nota-se que a diferença entre produzir uma história cujo tópico é mantido ao longo da narrativa (T3) e o tópico que aparece no início e retorna ao final (T2) é mais acentuada no $2^{\circ}$ ciclo, tendo em vista que os participantes apresentaram uma manutenção no tópico (T3) de $80 \%$, enquanto que no $1^{\circ}$ ciclo a diferença foi de $50 \%$.

O evento, o qual se constitui na trama ou situação problema que norteia o que é narrado e que envolve os personagens da história, quando se compara o desempenho entre os participantes do mesmo ciclo, nota-se uma tendência em apresentar o nível mais elaborado no $2^{\circ}$ ciclo, a diferença entre o (E2) e (E3) é de $60 \%$, enquanto que no $1^{\circ}$ ciclo esta diferença é de $20 \%$.

Por último, em relação ao desfecho da história, pode-se perceber que no $1^{\circ}$ ciclo, $50 \%$ das narrativas concentram-se no nível intermediário (D2); enquanto que $80 \%$ dos participantes do $2^{\circ}$ ciclo apresentam produções com o desfecho mais elaborado.

Após o levantamento dos indicadores da coerência enfatizados no presente estudo em relação às histórias produzidas pelos alunos, pôde-se optar pelo sistema de análise elaborado por Spinillo e Martins (1997) no estudo realizado com crianças.

O Teste Kruskal-Wallis revelou diferenças significativas entre os níveis de escolaridade $\left(1^{\circ}\right.$ ciclo vs. $2^{\circ}$ ciclo: $\chi^{2}$ 6,09, gl. 1, $p=0,0136)$, em relação aos níveis de coerência textual.

Nenhum dos participantes envolvidos no estudo produziu história no nível I. Nota-se que as histórias produzidas pelos participantes do $1^{\circ}$ ciclo encontram-se distribuídas nos níveis II, III e IV de forma semelhante.

No $2^{\circ}$ ciclo, a classificação das histórias produzidas concentram-se no nível IV, considerado mais elaborado, em virtude de não apresentar problemas em interligar os elementos estruturais contemplados nesse estudo, na medida que as produções analisadas neste grupo estabelecem uma íntima relação entre o desfecho e os outros aspectos que estruturam uma história.

Neste sentido, é possível pensar que o avanço do aluno em relação ao processo de escolarização formal e aquisição da leitura e da escrita favorece a manutenção dos indicadores da coerência acerca da produção de histórias.

Com base na informação obtida e através da documentação escolar dos alunos (registro de matrícula fornecidos pela secretaria da escola), foi possível realizar uma classificação dos participantes em relação a experiência escolar, conforme está disposto no item escolaridade da Tabela 2. Assim, de acordo com a disposição percentual dos níveis da coerência explorados nesse estudo pode-se realizar alguns comentários na perspectiva de tentar entender se a experiência escolar desses alunos exerce ou não algum tipo de influência na produção de histórias coerentes.

Os alunos que estão tendo contato com a educação formal pela primeira vez se apresentam distribuídos nos níveis II, III e IV de produção, apresentado uma concentração maior nos níveis II $(44,4 \%)$ e IV $(44,4 \%)$ (ver Tabela 3). Em relação aos alunos que chegaram a concluir a $1^{\mathrm{a}}$ série pode-se verificar que as histórias

Tabela 2

Freqüencia e (Porcentagens) de Histórias em cada Nivel em Função do Ciclo

\begin{tabular}{ccc}
\hline Nível & $1^{\mathrm{o}}$ ciclo & $2^{\mathrm{o}}$ ciclo \\
\hline I & $0(-)$ & $0(-)$ \\
II & $6(30)$ & $2(10)$ \\
III & $6(30)$ & $2(10)$ \\
IV & $8(40)$ & $16(80)$ \\
\hline
\end{tabular}


Tabela 3

Número (e Percentual) de Participantes, em cada Nivel da Coerência Textual, em

Funcão do Tempo de Experiência Escolar Apresentados no $1^{\circ} \mathrm{Ciclo}$

\begin{tabular}{clcc}
\hline Escolaridade & Nível II & Nível III & Nível IV \\
\hline $1^{a}$ Vez & $4(44,4)$ & $1(11,2)$ & $4(44,4)$ \\
$1^{a}$ série & $2(25)$ & $3(37,5)$ & $3(37,5)$ \\
$2^{a}$ série & $1(33,3)$ & $1(33,3)$ & $1(33,3)$ \\
\hline
\end{tabular}

produzidas foram classificadas nos níveis II (25\%), III $(37,5 \%)$ e IV $(37,5 \%)$. Do total dos participantes desse estudo $15 \%$ pertencentes ao $1^{\circ}$ ciclo chegaram a concluir a $2^{\mathrm{a}}$ série do ensino fundamental, os quais apresentam uma distribuição similar nos níveis II, III e IV, cujo percentual é de $33,3 \%$.

Ao observar os percentuais dos níveis III e IV, conjuntamente, pode-se verificar que a experiência escolar influência no estabelecimento da coerência, em situação de produção oral de histórias, visto que os alunos sem instrução formal apresentaram um percentual (nível III + IV) de 55,6\%. Ao passo que os alunos que cursaram até a $1^{\text {a }}$ série, apresentaram percentuais de $75 \%$, e os alunos que chegaram a cursar a $2^{\mathrm{a}}$ série apresentaram $66,6 \%$ de histórias nos níveis III e IV.

A queda no percentual dos participantes do $1^{\circ}$ ciclo com maior tempo de experiência escolar envolvidos no estudo, deveu-se ao fato de que a quantidade de participantes que cursaram a $1^{a}$ série foi maior do que os que cursaram a $2^{a}$ série. Provavelmente se houvesse mais produções nesse último grupo de alunos, teria se obtido percentuais mais elevados.

Este tipo de olhar em relação ao resultados obtidos no presente estudo, evidencia que mesmo tendo uma experiência escolar precária, com pouco domínio da leitura e da escrita, ainda assim, esta experiência se constitui num ganho, pois parece exercer uma certa influência no desenvolvimento da competência textual no aluno, em relação ao estabelecimento da coerência na produção de história.

No $2^{\circ}$ ciclo (ver Tabela 4), foi realizado o mesmo tipo de análise conduzido com os participantes do $1^{\circ}$ ciclo. Ao focalizar conjuntamente os percentuais das histórias produzidas pelos alunos do $2^{\circ}$ ciclo da escolarização básica de jovens e adultos nos níveis III e $\mathrm{IV}$, pode-se perceber um maior desempenho à medida que a escolarização aumenta. Os alunos que haviam cursado até $3^{a}$ série, apresentam $75 \%$ das produções classificadas no nível IV.Já os alunos com experiência escolar até a $4^{a}$ série, concentraram as produções no nível IV $(100 \%)$. Quanto à classificação das histórias dos alunos regulares da educação básica de jovens e adultos (E.J.A.), o percentual é de $92,9 \%$ (nível III + IV).

No geral, é possível pensar que o estabelecimento da coerência textual, em particular à história, em relação aos componentes estruturais, tende a melhorar com avanço da escolaridade do leitor/escritor.

Comparando os percentuais dos alunos do $1^{\circ}$ ciclo que estavam iniciando o processo de instrução formal, nos níveis III e IV $(55,6 \%)$ com os alunos do $2^{\circ}$ ciclo $(92,9 \%)$ egressos da educação básica de jovens e adultos, percebe-se que a escolarização formal e sistemática, especialmente na aquisição da leitura e da escrita, permite que o aluno desenvolva a habilidade de produzir oralmente um texto mais coerente.

\section{Discussão}

Através dos resultados obtidos, verificou-se que:

1) Há indicadores da coerência mais fácies de serem mantidos ao longo de uma narração do que outros.

2) De modo geral, constatou-se que a escolaridade influencia no estabelecimento da coerência.

3) Foi visto também que os alunos pertencentes ao mesmo ciclo, mas que apresentavam níveis de experiência escolar distintos, mesmo em condições precárias (Ex.: pouco domínio da leitura e da escrita) quanto à instrução

Tabela 4

Número (e Percentual) de Participantes, em cada Nivel da Coerência Textual, em

Função do Tempo de Experiência Escolar Apresentados no $2^{\circ}$ Ciclo

\begin{tabular}{cccc}
\hline Escolaridade & Nível II & Nível III & Nível IV \\
\hline $3^{\text {a }}$ série & $1(25)$ & $0(-)$ & $4(20)$ \\
$4^{\text {a }}$ série & $0(-)$ & $0(-)$ & $2(10)$ \\
E. J. A. & $1(7,1)$ & $2(78,6)$ & $14(70)$ \\
\hline
\end{tabular}


formal, apresentaram uma performance melhor do que os alunos sem nenhum tipo de escolarização.

4) Quando se comparou os alunos egressos da escolarização básica de jovens e adultos (alunos em nível inicial de alfabetização com alunos alfabetizados na escolarização básica de jovens e adultos), constatou-se que a escolarização sistemática influencia na produção oral de histórias mais coerentes.

Quanto ao primeiro aspecto - a influência da escolaridade na manutenção dos indicadores ao longo das narrativas - é possível verificar uma progressão dos indicadores da coerência em função do nível de escolaridade. Portanto, parece que um maior tempo de exposição ao ensino formal da leitura e da escrita favorece o processo de construção de sentido em situações de produção oral.

O sistema de análise utilizado no exame da coerência textual neste estudo permitiu identificar a dificuldade enfrentada por aquele que produz uma história, na medida em que este deve não só manter os indicadores ao longo da narrativa, mas sobretudo manter uma relação entre eles, formando uma cadeia narrativa coerente em sua totalidade.

A maior dificuldade encontrada foi em relação ao desfecho, resultado este que corrobora com o estudo desenvolvido por Spinillo e Martins (1997) com crianças. Desfechos que apresentam uma íntima relação com o evento principal e os demais indicadores presentes nas histórias (personagem, tópico e evento) de tipo mais elaborado (D3, T3, E3, P3) encontram-se nas produções de nível IV. Relacionar o desfecho de uma história com os demais indicadores se constitui numa tarefa cognitiva e lingüística bastante complexa.

Em termos cognitivos, como afirmado por Spinillo e Martins, ao produzir um desfecho compatível e coordenado com os eventos narrados anteriormente, três processos são realizados concomitantemente pelo produtor: o que está sendo produzido no momento (o desfecho da narrativa); o que já fora produzido (o desenvolvimento da narrativa: eventos); e a relação entre o que está sendo produzido (desfecho) com o que fora produzido (desenvolvimento). Ao produzir uma história coerente, o esforço do narrador recai sobre a tentativa de preservar em sua mente a cadeia narrativa anteriormente elaborada (o que envolve a memória de trabalho); e ainda, o estabelecimento de relações entre as diversas partes da história, coordenando-as e integrando-as (processamento do texto). Do ponto de vista lingüístico, a coordenação e integração dessas relações precisam ser expressas através das marcas lingüísticas características de cada texto. Isto parece ocorrer tanto entre criança como entre adultos, como mostram os resultados obtidos nesta investigação.
Em ambos os estudos, foram detectadas dificuldades específicas enfrentadas pelo aluno na produção de uma história coerente. Qual é o papel da escola para que sejam superadas essas dificuldades? Através dos resultados obtidos tanto por Spinillo e Martins como dos resultados obtidos no presente estudo é possível pensar na superação dessas dificuldades através do planejamento de situações didáticas, cuja ênfase incida sobre atividades pedagógicas que propiciem aos alunos refletir sobre as partes constituintes do texto, talvez através de atividades pedagógicas desta natureza o aluno irá entender a organização lingüística e a estrutura do texto.

Algumas considerações podem ser feitas em relação ao fato de que os alunos do $1^{\circ}$ ciclo com experiência escolar prévia, mesmo em condições precárias acerca do domínio da leitura e da escrita, apresentaram uma performance melhor do que os alunos em nível inicial de alfabetização. Estes alunos com experiência escolar prévia, provavelmente foram expostos a atividades pedagógicas que teve o texto como recurso didático no ensino de língua. Este comentário se constitui mais numa especulação para que seja melhor investigado em um estudo futuro, tendo em vista que o enfoque atual no ensino da língua, tratada nos referências curriculares nacionais ressaltam a importância de se alfabetizar o aluno a partir do texto e não em atividades que se destinam a aprendizagem de decodificar e codificar palavras.

No presente estudo também foi visto, através da comparação entre os alunos iniciantes e os alfabetizados na escolarização básica de jovens e adultos, que a sistematização do ensino influência a produção oral de histórias mais coerentes. Com base nesse resultado, é possível pensar que o aluno quando apresenta uma experiência escolar sistemática tem maior possibilidade de apresentar níveis de coerência textual mais elaborados. Talvez esta questão estaria relacionada tanto ao contato pessoal que o aluno possua com textos, como acerca do papel representado pela escola, com atividades pedagógicas que exploram o texto como recurso didático no processo de alfabetização.

Em relação aos níveis de produção observados no estudo de Spinillo e Martins com criança, verificou-se que crianças pré-escolares concentram-se nos níveis menos elaborados de produção (nível I + nível II). Nesta série, nenhuma história produzida foi classificada no nível IV. No entanto, as produções dos alunos da alfabetização e da $1^{a}$ série foram semelhantes concentrando-se nos níveis mais elaborados de produção (nível III e nível IV). Spinillo e Martins ressaltam a aquisição da leitura e da escrita como um fator importante acerca do desempenho das crianças na produção de histórias mais coerentes. No presente 
estudo foi verificado que as produções dos alunos do $1^{\circ}$ ciclo encontram-se distribuídos nos níveis II, III e IV. Enquanto que a maioria dos alunos do $2^{\circ}$ ciclo produz histórias no nível mais elaborado da coerência (nível IV).

A partir dos resultados obtidos neste estudo, assim como foi ressaltado inicialmente no estudo de Spinillo e Martins com as crianças, pode-se verificar que a aquisição da leitura e da escrita é muito importante no estabelecimento da coerência em situação de produção oral de histórias.

Entretanto, dois resultados encontrados no presente estudo se diferenciam dos resultados encontrados por Spinillo e Martins. No presente estudo nenhuma história produzida foi classificada no nível I, considerado o mais elementar. Também foi verificado que parte dos alunos matriculados no $1^{\circ}$ ciclo que não havia tido uma experiência escolar prévia, produziu histórias nos níveis mais elaborados da coerência. Sendo assim, como poderia se explicar o fato dos alunos que nunca foram à escola, terem produzido histórias no nível mais elaborado? Estes resultados parecem evidenciar que além da escolaridade, outros fatores (Ex.: conhecimento de mundo, conhecimento partilhado, fatores pragmáticos, etc.) influenciam a produção de histórias mais coerentes por jovens e adultos.

Segundo T. Carraher, D. Carraher e Schlliemann (1995), a cultura direciona o desenvolvimento da mente de forma que: aprendemos a língua falada por aqueles que nos cercam, e a partilhamos com pessoas que a utilizam. É possível que os adultos ao serem expostos a uma maior diversidade de experiências de vida compartilhem intensamente de instrumentos culturais (Ex.: leitura e escrita), mesmo que não os dominem do ponto de vista formal.

Para obter uma possível explicação acerca desses resultados, seria necessário se investigar o contato que estas pessoas têm com textos em situação fora da escola.

\section{Referências}

Beaugrande, R. de (1981). Text, discurse and processes. London/New York: Longman.

Beaugrande, R. de. (1996). New foundations for a science of text and discourse: Cognition, communication, and the freedom of access to knowledge and society. New Jersey: Norwood.

Beaugrande, R. de \& Dressler, W. U. (1981). Introduction to text linguistics. London: Longman.

Beaugrande, R. de \& Dressler, W. U. (1997). Introducción a la lingüística del texto. Barcelona: Ariel.

Bernárdez, E. (1982). Introdución a la lingüistica del texto. Madrid: Spasa Calpe.

Carraher, T., Carraher, D. \& Schiliemann, A. (1995). Na vida dez, na escola zero. São Paulo: Cortez.

Charolles, M. (1978). Introduction aux problémes de la cohérence des texts. Langue Française, 38, 7-41.
Charolles, M. (1979). Donnés empiriques et modélisation en grammaire de texte. Refléxion à partir du probleme de la coherence discursive. Langue et discours, 34, 75-79.

Fávero, L. L. \& Koch, I. G. V. (1988). Lingüistica textual: Introdução. São Paulo: Cortez.

Ferreira, A. L. (1999). Produção e consciência metalingüística de textos em crianças: Um estudo de intervenção. Dissertação de Mestrado não-publicada, Curso de Pós-graduação em Psicologia Cognitiva, Universidade Federal de Pernambuco. Recife, PE.

Halliday, M. A. K. \& Hasan, H. (1976). Coeson in english. London: Longman.

Hicks, D. (1991). Kinds of narrative: Genre skills among first graders from two communities. Em A. McCabe \& C. Peterson (Orgs.), Developing narrative structure. Hillsdale, N.J.: Lawrence Erlbaum.

Johnson, N. S. \& Mandler, J. M. (1980). A tale of two structures: Underlying and surface forms in stories. Poetics, 9, 51-86.

Koch, L. L. \& Fávero, I. G. V. (1991). Lingüistica textual: Introdução. São Paulo: Cortez.

Koch, I. G. V. \& Travaglia, L. C. (1999a). A coerência textual. São Paulo: Cortez.

Koch, I. G. V. \& Travaglia, L. C. (1999b). Texto e coerência. São Paulo: Contexto.

Mandler, J. M. \& Johnson, N. S. (1977). Remembrance of things parsed: Story structure and recall. Cognitive Psychology, 9, 111-151.

Marcuschi, L. A. (1983). Lingüística de texto: Como é e como se faz. Série Debates 1. Recife: Universidade Federal de Pernambuco.

Prince, G. (1973). A grammar for stories. The Hague: Mouton.

Rego, L. L. B. (1986). A escrita de histórias por crianças: As implicações pedagógicas do uso de um registro linguístico. Revista de Documentação de Estudos em Linguística Teórica e Aplicada, 2, 165-180.

Smith, F. (1988). Understanding reading: A psycholinguistic analysis of reading and learning to read. Hillsdale: Lawrence Erlbaum.

Spinillo, A. G \& Martins, R. A. (1997). Uma análise da produção de histórias coerentes por crianças. Psicologia: Reflexão e Crítica, 10, 219-248.

Spinillo, A. G. \& Pinto, G. (1994). Children's narratives under different conditions: A comparative study. British Journal of Developemental Psychology, 12, 177-193.

Spinillo, A. G. (1993). Era uma vez... e foram felizes para sempre: Esquema narrativo e variações experimentais. Temas em Psicologia, 1, 67-87.

Spinillo, A. G. \& Roazzi, A. (1988). Usos e funções da língua escrita no contexto escolar. Revista Brasileira de Estudos Pedagógicos, 69(161), 75-90.

Stein, N. L (1988). The development of children's storytelling skill. Em M. Franklin \& S. Barten (Orgs.), Children language: A reader (pp. 282-293). Oxford: Oxford University Press.

Stein, N. L \& Glenn, C. G. (1979). An analysis of story comprehension in elementary school children. Em R. O. Freedle (Org.), New directions in discursse processing (Vol. 2). New Jersey: Ablex.

Stein, N. L. \& Policastro M. (1984). The concept of story: A comparision between children's and teacher's viewpoints. Em H. Mandl, N. L. Stein \& T. Trabasso (Orgs.), Learning and comprehension of Text (pp. 112138). Hillsdale: Lawrence Erlbaum.

Tannen, D. (1982). Oral and literate strategies in spoken and written narratives. Language, 58, 1-21.

Tannen, D. (1984). Coherence in spoken and writen discourse. New Jersey: Ablex. Van Dijk, T. \& Kinitsch, W. (1983). Strategies of discourse comprehension. New York, NY: Academic Press.

Van Dijk, T. A. (1981). Studies in the pragmatics of discourse. Paris: Mouton.

Van Dijk, T. A. (1973). Some aspects of the text grammars. The Hague: Mouton. Widdowson, H. G. (1978). Teaching language as comunication. Oxford: Oxford University Press.

Recebido: 07/11/2001

$1^{a}$ revisão $21 / 06 / 2002$

Última revisão: 18/07/2002

Aceite final: $31 / 07 / 2002$

Sobre as autoras

Fabíola Gonçalves é Mestre em Psicologia Cognitiva pela Universidade Federal de Pernambuco.

Maria da Graça Bompastor Borges Dias é Professora do Programa de Pós-graduação em Psicologia Cognitiva

da Universidade Federal de Pernambuco. 